Provided for non-commercial research and education use. Not for reproduction, distribution or commercial use.

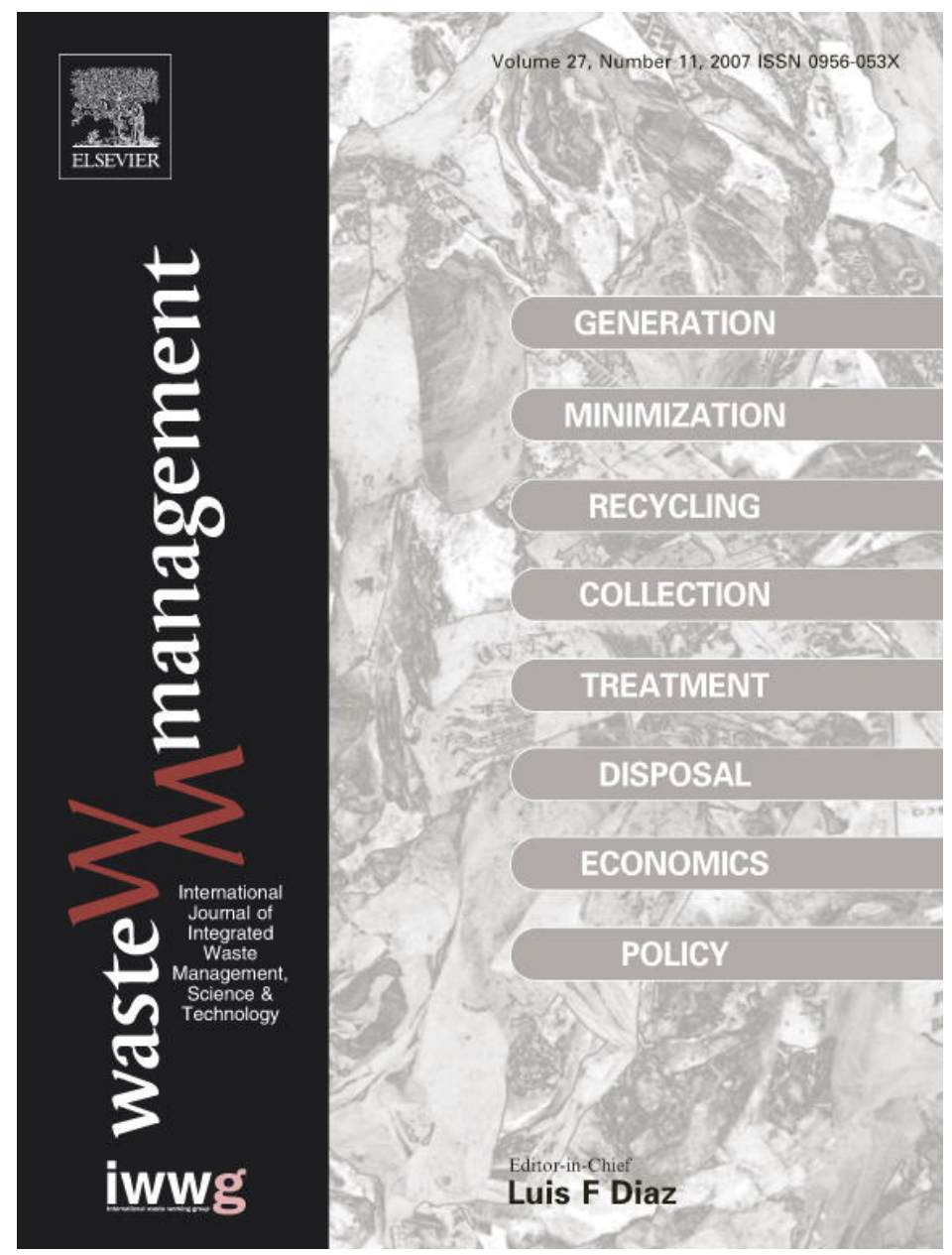

This article was published in an Elsevier journal. The attached copy

is furnished to the author for non-commercial research and education use, including for instruction at the author's institution, sharing with colleagues and providing to institution administration.

Other uses, including reproduction and distribution, or selling or licensing copies, or posting to personal, institutional or third party websites are prohibited.

In most cases authors are permitted to post their version of the article (e.g. in Word or Tex form) to their personal website or institutional repository. Authors requiring further information regarding Elsevier's archiving and manuscript policies are encouraged to visit:

http://www.elsevier.com/copyright 


\title{
A multiple criteria analysis for household solid waste management in the urban community of Dakar
}

\author{
Ka-Mbayu Kapepula ${ }^{\mathrm{b}}$, Gerard Colson ${ }^{\mathrm{a}, *}$, Karim Sabri ${ }^{\mathrm{b}}$, Philippe Thonart ${ }^{\mathrm{c}}$ \\ ${ }^{a}$ HEC Management School, University of Liege, B-4000 Liege, Belgium \\ ${ }^{\mathrm{b}}$ University of Liege, B-4000 Liege, Belgium \\ c Agronomic Faculty of Gembloux, University of Liege, B-4000 Liege, Belgium
}

Accepted 21 July 2006

Available online 24 October 2006

\begin{abstract}
Household solid waste management is a severe problem in big cities of developing countries. Mismanaged solid waste dumpsites produce bad sanitary, ecological and economic consequences for the whole population, especially for the poorest urban inhabitants. Dealing with this problem, this paper utilizes field data collected in the urban community of Dakar, in view of ranking nine areas of the city with respect to multiple criteria of nuisance. Nine criteria are built and organized in three families that represent three classical viewpoints: the production of wastes, their collection and their treatment. Thanks to the method PROMETHEE and the software ARGOS, we do a pair-wise comparison of the nine areas, which allows their multiple criteria rankings according to each viewpoint and then globally. Finding the worst and best areas in terms of nuisance for a better waste management in the city is our final purpose, fitting as well as possible the needs of the urban community. Based on field knowledge and on the literature, we suggest applying general and area-specific remedies to the household solid waste problems.
\end{abstract}

(c) 2006 Elsevier Ltd. All rights reserved.

\section{Introduction}

In developing countries, household solid waste management (HSWM) in large cities is often mismanaged, resulting in severe consequences for the urban population such as high rates of morbidity, aesthetic degradation, economic losses produced by flood propagation or simply by the absence of waste valorisation through recycling and recovery. Sometimes, like in Dakar, poor people live too close to a huge landfill. At the same time, informal activities are developed around the solid waste activities, which can enrich some intermediaries working without any official allowance. Cities try to solve some of these problems by calling for foreign private companies or for NGOs to improve the collection and the valorisation of solid wastes.

\footnotetext{
* Corresponding author. Tel.: +32 43663188 .

E-mail address: g.colson@ulg.ac.be (G. Colson).
}

For instance, in Dakar, a Senegal-Canadian consortium is in charge of collecting and transporting wastes and in managing the landfill. A Swiss company even proposed to invest up to 5 billions of FCFA per year $(€ 7,622,450)$ for the development of a "composting" industry.

However, the problem is still growing, with the following trends:

- The rapid population growth produces more and more urban wastes that are not sorted and are considered as valueless by inhabitants, except for some small parts purchased by itinerant informal merchants. This growth is mainly a result of the migration of starving people from rural areas to the peri-urban areas, where they build slums with the hope of improving their situation. This phenomenon is especially the case in Dakar.

- Solid wastes are not always collected and sometimes are thrown anywhere by the population, resulting in dumps that are causes of epidemics and floods. 
- The collection and the transportation of increasing quantities of waste are difficult in several unstructured areas of the city with their twisting and narrow streets, their absence of passable ways and the deterioration of existing ones.

- Increasing the public health impacts, all these phenomena are of increasing concern.

- Ignoring clever sorting and economic valorisation of wastes, a great majority still perceives solid wastes as a pure nuisance.

Facing this difficult situation, several remedies have been tried in several countries:

- Private/public partnerships (Shafiul and Mansoor, 2004).

- Acknowledgement of the informal sector by authorities and organization of scavenger cooperatives (Medina, 2000).

- Improvement of the financing for sustainability (McBean et al., 2005).

- Dealing with problems via strategic or systemic approaches (Kum et al., 2005; Ericson et al., 2005).

- Involvement of the community in waste management (Mongkolnchaiarunya, 2005).

- Remedies for general improvement, like in Kenya (Rotich et al., 2006).

Also, note that an informal economy exists where some people make money from the recovery of metals and plastics from solid wastes. Generally, this informal economy produces little benefit for the population and escapes taxation by the public authority, resulting in no real improvement of the sanitary, environmental and economic situations of the city.

At the end of this paper, we will propose some tracks of local improvement of HSWM, inspired by our field knowledge and by a possible involvement of the people in HSWM, following some successes achieved in other domains by micro-finance. These suggestions are partly based on the results of research conducted in 1998 in Dakar, of which the conclusions were sufficiently validated by several studies conducted in Dakar by Kapepula and Thonart during the period 1998-2005. Some of these suggestions for remediation have been validated in other parts of the world by their successful application.

For an application of differentiated remedies to the local HSWM problems of different parts of the city, we propose first building several indicators of nuisance, and then ranking nine subdivisions of the city in terms of household solid waste (HSW) nuisance, perceived and observed by their populations. Such a ranking of the nine areas may facilitate the step of discovering the reasons behind the relative high or low levels of nuisance in the different areas examined, and their specific remedies.

The main purpose of this paper is to present a methodology focusing on multiple criteria analysis and ranking of the nine areas of Dakar. From the extensive literature on Multiple Criteria Decision Aids (MCDA) (e.g., Colson and De Bruyn, 1989; Roy, 1996; Vincke, 1992) we chose the well-known PROMETHEE method by Brans et al. (1986) that has been used in hundreds of applications. Since we want an integrated approach with two levels of analysis, we use the software ARGOS (Colson, 2000). This device allows dealing with the MCDA methodology, including PROMETHEE II and III $^{1}$ with several judges or families ${ }^{2}$ of criteria. This tool deals with the problem in two stages. The first stage is a classical ranking of items (areas in this case) according to the basic chosen criteria. The second stage exploits the second level of the hierarchy of criteria, i.e., the analysis of the criteria families. This latter analysis is performed using the JUDGES software (Colson and Mareschal, 1994), which is included in Argos.

The paper is divided into five sections. After this introduction, Section 2 is devoted to a short presentation of the collected data and of the nine chosen criteria aggregated in three families. Next, Section 3 is a brief recall of PROMETHEE II and III and of the two used visuals provided by the JUDGES software. Section 4 interprets the results of our study with a thorough knowledge of areas gained through the numerous visits done by our experts during the period 1998-2005. The last section presents some general and area-specific remedies for HSW problems of Dakar, which have emerged from our visits and have been developed further by our multiple criteria ranking and the consultation of the literature.

\section{Collected data, nuisance criteria and their families of aggregation}

\subsection{Collected data}

Data were collected in 1998 for the community of Dakar $^{3}$ in nine areas that were the subdivisions of greater Dakar, i.e., the city with all of its peri-urban areas. As is common in developing countries, big cities have some developed areas where the services and the roads infrastructure are more advanced. We call these the structured areas (SA) since all the urban facilities are managed similarly to developed countries. Four areas are structured in Dakar, and their inhabitants are generally richer and possibly more educated to modern management than the inhabitants of the five other areas, called unstructured

\footnotetext{
${ }^{1}$ This third release by Brans et al. (1984) is rarely applied, but very interesting according to our long MCDA experience.

${ }^{2}$ In this paper, we will, without differentiation, use the terms of judges, families or points of view for designating the three families of criteria in the multiple criteria and multiple judges analyses that will be performed.

${ }^{3}$ We did not have the possibility of reproducing or updating the research. The results and the rankings issued from these data must be considered with caution due to probable changes during the period 19982005. However, our two experts confirm that the observed changes during their numerous visits are unfortunately giving an impression of degradation of HSWM, especially in poorer unstructured areas.
} 
areas (UA) with respect to a general 'laissez aller' that predominates in those poorer areas. Regarding waste management, the roads inside these UA are narrower, less passable or even non-passable by trucks or cars, and people tend to neglect waste management.

Our general objective is to compare the nine areas according to three general points of view of waste management, which are the production, the collection and the treatment of solid wastes produced by households in each area. Now, we have to build criteria capturing this general objective of measuring a relative nuisance. This requirement is strongly restricted by the difficulty of data collection in the field.

From the production point of view, an enquiry allowed us to estimate the percentage of people in each area that produces each increment of generation $(\mathrm{kg} /$ day) of wastes from $0-2.9 \mathrm{~kg}$ to $18 \mathrm{~kg}$ and more. Table 1 allows a comparison of the distributions of waste production in SA versus in UA areas.

Although the numbers of surveyed households $(\mathrm{H})$ are nearly the same in both types of areas, UA people produce smaller amounts of HSW than SA people. This sample tends to confirm a generally observed rule that richer people produce more garbage than poorer people. Note that some poor people coming from unstructured areas pick up some HSW in structured areas for the purpose of sorting them and making some money before throwing away the residues from the collected HSW in their own areas. This behaviour increases the amount of uncollected waste that is produced in the unstructured areas.

From the collection point of view, we first consider means of HSW transportation by the households (Table 2).

Obviously again, modern means of collecting HSW are more often used in SA, while $50 \%$ of UA people must convey their garbage by foot toward the closest intermediary disposal containers located in each area. Table 3 tends to confirm this latter observation in showing, between households of both UA and SA zones, the difference of walking distance for disposing their garbage in a collection location.

Table 1

Distribution of households by HSW production in SA versus UA areas in Dakar

\begin{tabular}{llll}
\hline $\begin{array}{l}\text { Respondents in } \\
\text { structured areas }\end{array}$ & $\%$ & $\begin{array}{l}\text { Respondents in } \\
\text { unstructured areas }\end{array}$ & $\%$ \\
\hline $0-2.9 \mathrm{~kg} /$ day & 10.87 & $0-2.9 \mathrm{~kg} /$ day & 35.19 \\
$3-5.9 \mathrm{~kg} /$ day & 28.27 & $3-5.9 \mathrm{~kg} /$ day & 51.85 \\
$6-8.9 \mathrm{~kg} /$ day & 23.91 & $6-8.9 \mathrm{~kg} /$ day & 12.96 \\
$9-11.9 \mathrm{~kg} /$ day & 21.74 & $9-11.9 \mathrm{~kg} /$ day & 0 \\
$12-14.9 \mathrm{~kg} /$ day & 10.87 & $12-14.9 \mathrm{~kg} /$ day & 0 \\
$15-17.9 \mathrm{~kg} /$ day & 2.17 & $15-17.9 \mathrm{~kg} /$ day & 0 \\
18 and more kg/day & 2.17 & 18 and more kg/day & 0 \\
& $100 \%$ & & $100 \%$ \\
Number of H respondents & 46 & Number of H respondents & 54 \\
\hline
\end{tabular}

Data source: Enquiry by A. Kamaye, DEA in environmental studies, Faculty of Economics, University of Dakar, 1998.
Table 2

Distribution of households by HSW transportation means in SA and UA areas in Dakar

\begin{tabular}{llll}
\hline $\begin{array}{l}\text { Respondents in } \\
\text { structured areas }\end{array}$ & $\%$ & $\begin{array}{l}\text { Respondents in } \\
\text { unstructured areas }\end{array}$ & $\%$ \\
\hline "Hand-cart" & 2.17 & "Hand-cart" & 3.70 \\
Containers/by foot & 10.87 & Containers/by foot & 50.00 \\
Packer bodies/trucks & 86.96 & Packer bodies/trucks & 46.30 \\
& $100 \%$ & & $100 \%$ \\
Number of H respondents & 46 & Number of H respondents & 54 \\
\hline
\end{tabular}

Data source: Enquiry by A. Kamaye, DEA in environmental studies, Faculty of Economics, University of Dakar, 1998.

Table 3

Distribution of households by walking distances between homes and collection locations in Dakar

\begin{tabular}{llll}
\hline $\begin{array}{l}\text { Respondents in } \\
\text { structured areas }\end{array}$ & $\%$ & $\begin{array}{l}\text { Respondents in } \\
\text { unstructured areas }\end{array}$ & $\%$ \\
\hline Less than $20 \mathrm{~m}$ & 41.30 & Less than $20 \mathrm{~m}$ & 27.78 \\
$11-20 \mathrm{~m}$ & 13.04 & $11-20 \mathrm{~m}$ & 11.11 \\
$21-50 \mathrm{~m}$ & 10.87 & $21-50 \mathrm{~m}$ & 22.22 \\
$51-100 \mathrm{~m}$ & 10.87 & $51-100 \mathrm{~m}$ & 12.96 \\
$101-150$ & 2.17 & $101-150$ & 7.41 \\
More than 150 m & 21.75 & More than $150 \mathrm{~m}$ & 18.52 \\
& $100 \%$ & & $100 \%$ \\
Number of H respondents & 46 & Number of H respondents & 54 \\
\hline
\end{tabular}

Data source: Enquiry by A. Kamaye, DEA in environmental studies, Faculty of Economics, University of Dakar, 1998.

The walking distance required for disposal is generally due to the inadequacy of roads and streets for the use of modern collection vehicles (compactor trucks and packer bodies).

Let us observe then the differences in frequency of collection in each zone (Table 4).

The modal frequency of collections is three times per week $(>54 \%)$ in the SA zone, while it reaches seven times per week in the UA zone $(>40 \%)$. Inhabitants in UA generally convey their garbage in bulk, while richer people in SA tend to place their garbage in bags, implying fewer trips even for a higher total conveyed amount.

From the point of view of disposing of garbage, an enquiry has estimated five different ways of treating HSW

Table 4

Distribution of households by frequency of HSW collections per week in Dakar

\begin{tabular}{|c|c|c|c|}
\hline $\begin{array}{l}\text { Respondents in } \\
\text { structured areas }\end{array}$ & $\%$ & $\begin{array}{l}\text { Respondents in } \\
\text { unstructured areas }\end{array}$ & $\%$ \\
\hline Once per week & 2.17 & Once per week & 5.56 \\
\hline Twice per week & 32.61 & Twice per week & 22.22 \\
\hline Three per week & 54.65 & Three per week & 27.78 \\
\hline Four per week & 0 & Four per week & 0 \\
\hline Five per week & 0 & Five per week & 0 \\
\hline Six per week & 0 & Six per week & 3.70 \\
\hline Seven per week & $\begin{array}{l}10.87 \\
100 \%\end{array}$ & Seven per week & $\begin{array}{l}40.74 \\
100 \%\end{array}$ \\
\hline Number of $\mathrm{H}$ respondents & 46 & Number of $\mathrm{H}$ respondents & 54 \\
\hline
\end{tabular}

Data source: Enquiry by A. Kamaye, DEA in environmental studies,

Faculty of Economics, University of Dakar, 1998. 
in each area: by burning, by burying, by throwing in brooks or street-kennels, by throwing in open spaces, or by other ways.

Two other points of view were also treated: (1) the willingness to pay fees for the HSW collection and treatment (Table 5) and (2) the HSW nuisance perception by inhabitants of each area.

The willingness to pay fees for garbage service is actually the answer of households to the question: "How much are you ready to pay for this garbage service?" The answer is an indicator of the opinion of people about this problem and also of the sanitary and ecological concern of the population targeted by the enquiry. The majority of respondents in both zones do not want to pay more than 2000 FCFA (€3.048). No household in the UA is ready to go higher than 4000 FCFA (€6.096) versus more than $17 \%$ in SA. A very surprising outcome is that nearly one inhabitant in two $(>47 \%)$ in SA is not ready to pay more than 1000 FCFA (€1.524) versus $22 \%$ in UA. So richer people producing more garbage and having more sophisticated means of collecting HSW, tend to be more reluctant to pay taxes for managing with their HSW.

Let us finally observe that the answers to the simple question: "Is the actual HSW problem a nuisance for you?" reveal no significant difference in the positive

Table 5

Distribution of households by their willingness to paying taxes for the HSW collection and treatment in Dakar (responses in FCFA of 1998; 1000 FCFA $=1.524$ euros)

\begin{tabular}{llll}
\hline $\begin{array}{l}\text { Respondents in } \\
\text { structured areas }\end{array}$ & $\%$ & $\begin{array}{l}\text { Respondents in } \\
\text { unstructured areas }\end{array}$ & $\%$ \\
\hline $0-1000$ & 47.82 & $0-1000$ & 22.22 \\
$1001-2000$ & 17.39 & $1001-2000$ & 35.19 \\
$2001-3000$ & 8.70 & $2001-3000$ & 20.37 \\
$3001-4000$ & 8.69 & $3001-4000$ & 22.22 \\
$4001-5000$ & 10.87 & $4001-5000$ & 0 \\
$>5000$ & 6.52 & $>5000$ & 0 \\
& $100 \%$ & & $100 \%$ \\
Number of H respondents & 46 & Number of H respondents & 54 \\
\hline
\end{tabular}

Source: Enquiry by A. Kamaye, DEA in environmental studies, Faculty of Economics, University of Dakar, 1998. responses in each zone $(\mathrm{SA}=87 \%$; $\mathrm{UA}=85 \%)$. In the sample, nearly everybody is aware of the nuisance caused by solid wastes in the city.

It remains to try measuring this nuisance for each area using the nine following criteria, aggregated in the three families, each family being built for capturing, as far as possible by available data, one of the three aforementioned objectives or points of view.

\subsection{Nine criteria aggregated in three families of objectives}

Our main purpose was to measure the global nuisance of garbage in each of the nine areas of Dakar in order to compare these areas by pair-wise comparisons. The final objective is to point out the worse and the better areas in terms of nuisance with a view of finding, maybe in a further study, examples of best practice to solve the HSW problem. The list of nine criteria of nuisance is presented in Table 6.

\section{Criterion 1}

Average quantity of waste produced by household

This criterion is the sum of wastes in kilograms disposed during 1 week by a category of household, weighted by the number of households in this category, divided by the number of households in the area.

\section{Criterion 2}

Number of households in an area (Table 7)

We assume that a larger number of households represents a potential risk of waste growth for an area. We have estimated the number of households by using the known number of inhabitants per area and the distribution of household percentages.

\section{Criterion 3}

Average duration between two successive HSW collections This is the inverse of the third criterion of the collection family of criteria, i.e. of the sixth criterion, here after. We have observed on the field that a low frequency of waste

Table 6

Nine criteria of nuisance with their aggregation in three families or HSWM points of view

\begin{tabular}{|c|c|c|c|c|c|c|c|c|c|c|}
\hline \multirow[t]{2}{*}{ Families (Units) } & \multirow[t]{2}{*}{ Criteria } & \multicolumn{4}{|c|}{ Structured areas (SA) } & \multicolumn{5}{|c|}{ Unstructured areas (UA) } \\
\hline & & $\mathrm{Z1}$ & $\mathrm{Z} 2$ & $\mathrm{Z3}$ & $\mathrm{Z} 4$ & $\mathrm{Z5}$ & Z6 & $\mathrm{Z7}$ & $\mathrm{Z8}$ & Z9 \\
\hline \multicolumn{11}{|c|}{ Production (kg/H, week)-(Week/Times) } \\
\hline & Volume of wastes per household & 5.81 & 9.09 & 7.69 & 8.47 & 4.34 & 2.70 & 4.34 & 2.77 & 5.88 \\
\hline & Estimated number of $10^{3}$ households & 19.1 & 36.6 & 8.3 & 28.5 & 25.1 & 38.0 & 27.5 & 14.2 & 3.8 \\
\hline & Duration between two collections & 0.37 & 0.33 & 0.19 & 0.40 & 0.29 & 0.22 & 0.26 & 0.16 & 0.14 \\
\hline \multicolumn{11}{|c|}{ Collection (Times/Week) } \\
\hline & Use of means of collection & 0 & 0.10 & 0.71 & 0 & 0.65 & 0.4 & 0.62 & 0 & 0 \\
\hline & Resistance to pay the HSWM taxes & 6.33 & 10.5 & 29.4 & 5.75 & 3.45 & 9.80 & 50 & 12.5 & 100 \\
\hline & Frequency of collections & 2.73 & 3 & 5.14 & 2.5 & 3.5 & 4.5 & 3.93 & 6.62 & 7 \\
\hline \multicolumn{11}{|l|}{ Treatment $(m)$} \\
\hline & Walking distance by household & 22.8 & 79 & 110 & 68.2 & 62.3 & 9.5 & 100 & 132 & 35.5 \\
\hline & Cultural means of HSW elimination & 3.27 & 4.60 & 4.71 & 4.00 & 4.60 & 4.05 & 4.39 & 4.90 & 4.00 \\
\hline & Perceived nuisance by household & 0.87 & 0.80 & 0.83 & 0.83 & 0.60 & 0.83 & 0.83 & 1 & 1 \\
\hline
\end{tabular}


Table 7

Number of inhabitants and households in the nine areas in 1998

\begin{tabular}{llcccccc}
\hline Areas & Z1 & Z2 & Z3 & Z4 & Z5 & Z6 & Z7 \\
\hline Number of inhabitants in thousands & 190 & 364 & 83 & 284 & 287 & 435 & 315 \\
Estimates of number of $10^{3}$ households & 19.1 & 36.6 & 8.3 & 28.5 & 162 & 43 \\
\hline
\end{tabular}

Data source: Computation with data issued from: Direction de la prévision et de la statistique, 1999.

collections in an area tends to induce poor behaviour such as a spreading of the thrown wastes through the area. Obviously, the sole criterion obtained by the product of criteria 1 and 2 is sufficient to give a rough picture of the waste production. This first ranking of the area's household waste production was shown in Table 8. According to this rough estimate, the structured area $\mathrm{z} 2$ is far ahead of the other areas, being the largest producer of wastes, while $\mathrm{z} 9$ is the least polluting area. These issues, without the third criterion, should be considered as a partial viewpoint of production nuisance, while multiplying two criteria is too compensatory.

\section{Criterion 4}

Use of adequate means for collecting the HSW

In the structured areas, it is preferable to use compactor trucks or packer bodies for collecting the waste, while using other means is inadequate. The reverse is true for the unstructured areas. Consequently, we have designed a binary nuisance variable, which takes the value of 0 for a SA household responding that the collection is done by packer bodies/trucks, and the value of 1 if the collection is done by another method. These values are reversed for the same responses given in unstructured areas, i.e., the value is 1 when packer bodies or compactor trucks are used in UA, and the value is 0 when other means are used. Then, we compute the ratio of nuisance in each area. For instance, in area $1, z 1$, where the 11 respondents said that the fitted mean (bodies/truck) is used, the ratio is $0 / 11=0$, illustrating the perfect fit to this structured area's need. In area $\mathrm{z} 5$, 13 among the 20 respondents said that bodies/trucks are used while the others told us that another means is used. Therefore, the ratio of nuisance is $13 / 20=0.65$ for this unstructured area z5.

\section{Criterion 5}

Resistance of households to the payment of HSWM taxes The enquiry asked to households: "How much are you ready to pay taxes for implementing the transportation, collection and treatment of the HSW?' We computed the average amount given by the respondents in each area, i.e., the mean payment of HSW taxes accepted by a household in a given area. By taking the inverse of this amount, we obtained an indicator of the resistance of households to pay for HSWM in each area. If the resistance of an area increases, it is in turn an indicator of potential nuisance regarding collection in this area.

The authors acknowledge the subjectivity of this criterion, depending on the evaluation given by the respondents.

\section{Criterion 6}

Frequency of HSW collections during one week

While criterion 3 was the duration between two collections in 1 week, expressed in terms of a fraction of a week, here we consider its inverse, that is the frequency of HSW collections in 1 week, expressed in the number of times per week. We observed from criterion 3 that a longer duration increases the risk of HSW spreading in open spaces. Here a shorter duration, and thus a higher frequency of collection, would increase the cost of collecting and possibly the resistance to pay taxes. The existence of two opposite faces of a criterion will induce negatively correlated rankings of nuisance for the areas, according to the two points of view: HSW production and HSW collection. We observe that this double interpretation of the collection frequency points out a classical opposition between the risk and the cost of its reduction. However, note that the frequency of collection is also a virtual commodity for the population.

\section{Criterion 7}

Mean walking distance to a HSW collector, expressed in meters

This criterion intends to measure the difficulty for the households to deal with their garbage and also the risk of its being spread in open spaces, which is of course a very poor way of handling the HSW.

\section{Criterion 8}

Degree of severity of nuisance depending on the chosen cultural means for HSW elimination

Here, a scale of degree of severity of nuisance was proposed: 10 for burning, five for burying, four for throwing garbage into the street, two for disposal in a virgin space and one for other means. This scale was designed to reflect the relative perceived importance of the induced nuisance. Then, the weighted average gravity for each area was computed.

Table 8

Rough ranking of waste productions of the nine areas according to an estimate of waste production

\begin{tabular}{|c|c|c|c|c|c|c|c|c|c|}
\hline Areas & $\mathrm{Z} 2$ & $\mathrm{Z} 4$ & $\mathrm{Z7}$ & $\mathrm{Z1}$ & $\mathrm{Z} 5$ & Z6 & $\mathrm{Z3}$ & $\mathrm{Z8}$ & Z9 \\
\hline Tons of household wastes per week & 333 & 242 & 120 & 111 & 109 & 103 & 64 & 39 & 22 \\
\hline
\end{tabular}




\section{Criterion 9}

Subjective evaluation by the respondents of the existence of a $H S W$ nuisance The proportion of yes answers given by all respondents in an area to the question: "Is the actual HSW problem a nuisance for you?" is a subjective estimation of the perception of nuisance by the inhabitants of this area.

\section{Multiple criteria rankings of the nine areas by PROMETHEE II and III and by ARGOS}

\subsection{Methodology}

We perform a multiple criteria ranking of the areas using the well-known pair-wise methods PROMETHEE II and III, included in software ARGOS. The choice of this software is justified by its capability to easily perform an analysis with two stages. First, we operate three multiple criteria rankings using PROMETHEE II and III, one per point of view. The three rankings are saved at the end of the first stage; the second stage consists in comparing these rankings via some of the multiple judges' tools provided by ARGOS. A point of view will play the role of a judge of nuisance. Using software JUDGES, as part of this stage, we display its first two visuals that are the box plotting of the nine areas ranked by the three judges and the simple linkage hierarchical clustering of the three rankings. Finally, we provide a general multiple criteria and multiple judges ranking of the nine areas thanks to the function of BORDA. This last function supplies a global index of nuisance for these areas.

Obviously a simple and naive method of ranking, using the sums of ranks given by each criterion, could have given a first look at the global ranking under consideration. However, the multiple criterion literature has sufficiently showed that we avoid pitfalls of compensation and effects of imprecision, and gain more nuances by using its now classical tools and methods.

First, we want to avoid the compensation effect, which deletes the information included in an unbalanced multicriteria profile of the items to be ranked.

Second, we use pseudo-criteria rather than true or classical ones. This kind of criterion has the advantage of coping with the weak precision of data, by using two thresholds of decision. A first one $(q)$ allows the user to define an interval $[-q,+q]$ on the difference of values of two given areas, inside of which there is an indifference $(I)$ between them according to the considered criterion due to the too weak observed difference. Outside this interval, the pseudo-crite- rion will not immediately conclude to a strong or sure preference for one area, but a second threshold $(p)$ allows a distinction between a weak preference and a strong or sure preference. If the absolute difference of values between both areas is greater or equal to $p$, we consider that the preference for one of them is clear or sure and it will be qualified as a strong preference $(P)$ in favour of the best-valued area. The weak preference $(Q)$ will be decided in a different way. Indeed, if the difference between the values is inside one of the intervals $[-p,-q]$ or $[+q,+P]$, it is insufficient to decide a strong preference but sufficient to conclude to a rejection of the indifference, and to decide a weak preference.

The pseudo-criterion can be summarized by the sketch in Fig. 1, where $d(a, b)$ stands for the difference of values in favour of " $a$ " when it is positive, and in favour of " $b$ ", when it is negative ( $a$ and $b$ are the two compared areas).

Note that if $q$ is the only threshold, the pseudo-criterion becomes a quasi criterion with only two possible decisions: indifference or preference. The pseudo-criterion becomes a true criterion if $q=p=0$, i.e., a criterion without thresholds. The latter case of true criterion is obviously the usual criterion with an infinite power of discrimination (which is generally ignored by the common user).

The problem of choice of the threshold values has been discussed elsewhere (Colson and Mbangala, 1998). In our case, we have considered the following thresholds, $q$ and $p$, which are, respectively, $5 \%$ and $25 \%$ of the maximum range of observed values for the nine criteria (Table 9).

The PROMETHEE II method is an outranking multiple criteria device that provides an order of items by making pair wise comparisons of these items (areas in this case), first for each criterion, and then for all criteria. The final ranking is obtained according to the decreasing order of the preference flows of the items.

Among the six kinds proposed by the method, we used only one kind of criterion: the pseudo-criterion with a linear preference between the two thresholds (see Fig. 2).

Let $a$ and $b$ stand for two items and let $\mathbf{d}(\mathbf{a}, \mathbf{b})$ be the difference of their evaluations on a criterion c. We assume that a positive $\mathbf{d}(\mathbf{a}, \mathbf{b})$ corresponds to a preference for $a$ over $b$. The preference function $P(d(a, b))$ is assumed to take the value 1 as soon as the preference is strong (= clearly stated), i.e., when $|d|>p$, the preference threshold, and is assumed to take the value 0 when an indifference between $a$ and $b$ is decided, since their evaluation difference does not reach the threshold $q$. Between these two decisions, a weak preference is expressed and $P$ linearly increases with $|d|$.

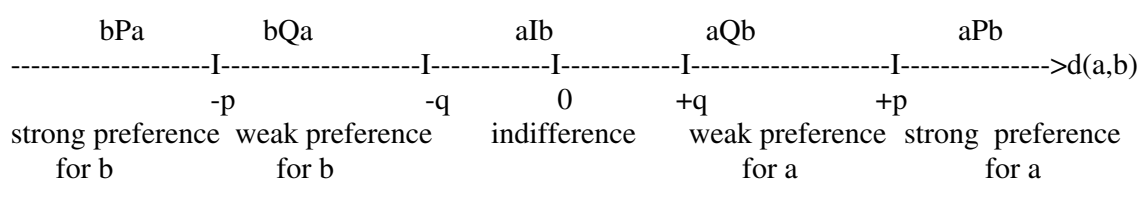

Fig. 1. The five preference decisions for a pseudo-criterion. 
Table 9

Threshold values of the nine chosen pseudo-criteria

\begin{tabular}{|c|c|c|c|c|c|c|c|c|c|}
\hline Criteria & $c 1$ & $c 2$ & $c 3$ & $c 4$ & $c 5$ & $c 6$ & $c 7$ & $c 8$ & $c 9$ \\
\hline Maximum observed values & 9.09 & 43.5 & 0.4 & 0.714 & 100 & 7 & 132. & 4.89 & 1 \\
\hline Minimum observed values & 2.7 & 19 & 0.14 & 0 & 3.45 & 2.5 & 9.5 & 3.27 & 0.6 \\
\hline Ranges & 6.39 & 24.5 & 0.26 & 0.714 & 96.55 & 4.5 & 122.5 & 1.62 & 0.4 \\
\hline Indifference thresholds $(q)$ & 0.32 & 1.22 & 0.013 & 0.036 & 4.83 & 0.225 & 6.133 & 0.081 & 0.02 \\
\hline (Strong) Preference thresholds $(p)$ & 1.59 & 6.12 & 0.064 & 0.178 & 24.13 & 1.125 & 30.67 & 0.405 & 0.10 \\
\hline
\end{tabular}

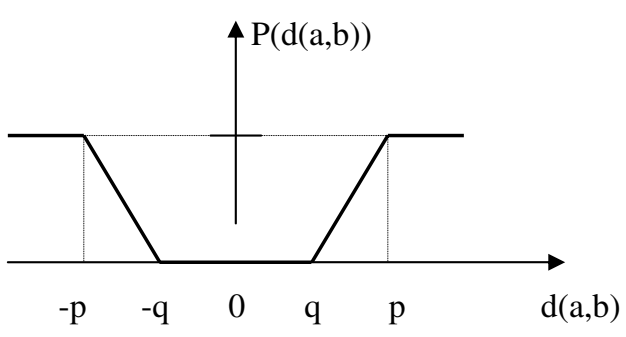

$\mathrm{P}(\mathrm{d})=0 \quad$ if $|\mathrm{d}|<\mathrm{q}$, there is indifference

$\mathrm{P}(\mathrm{d})=1 \quad$ if $|\mathrm{d}|>\mathrm{p}$, there is a strong preference

$\mathrm{P}(\mathrm{d})=(\mid \mathrm{d} l-\mathrm{q}) /(\mathrm{p}-\mathrm{q})$ else , there is a weak preference

Fig. 2. The linear pseudo-criterion.

Thus, this criterion states that $a$ is surely preferred to $b$ when $P(d(a, b))=1$. For the sake of simplicity, let us write $P_{c}(a, b) \equiv P_{c}(d(a, b))$ : the preference function for the criterion $c$.

The method defines then a multi-criteria preference index as the weighted average of the preference functions $P_{c}$ for all criteria. In our application, we considered that the three criteria of each point of view had the same weights. The index $\Phi(a, b)$ is computed by the next equation:

$\Phi(a, b)=\left(P_{1}(a, b)+P_{2}(a, b)+P_{3}(a, b)\right) / 3$

This index is called the (multi-criteria) preference flow of $a$ over $b$. We are more confident that $\mathrm{a}$ is preferred to $\mathrm{b}$ according to all criteria of the considered family, when the flow value is closer to 1 . Of course, $a$ is surely preferred to $b$, when the unanimity of criteria is in favour of a, and $\Phi(a, b)=1$ then. At this stage, PROMETHEE proposes to build a graph on the set $\mathrm{K}$ of considered items: its nodes are all of the compared items: $a, b, c, \ldots$ of $K$; the arcs joining two items are valued by $\Phi(a, b)$ and $\Phi(b, a)$ for a pair $(b, a)$. Then, the method computes two flows for an item $a$ :

$\Phi^{+}(a)=\Sigma_{b \in K} \Phi(a, b)$ : the leaving flow;

$\Phi^{-}(a)=\Sigma_{b \in K} \Phi(b, a):$ the entering flow

One may interpret the leaving flow as a multi-criteria force of preference of $a$ on the other items in $K$, and the entering flow as a multi-criteria preference weakness of $a$.
In PROMETHEE II, a balance of flows is completed, delivering a net preference flow for each item $a$ on all of the others items and for all criteria of the family:

$\Phi(a)=\Phi^{+}(a)-\Phi^{-}(a)$ : the net flow in favour of $a$

Usually, by ranking the net flows in a decreasing order, we obtain the preference ranking of the items, the positive flows being associated to the dominating items and the negative ones to the dominated ones. A very important point must be made here: we are searching for results regarding the level of nuisance and, accordingly, we have conserved positive flows for the areas dominating the others in terms of nuisance. Obviously, however, one prefers fewer nuisances to more, so that we could have changed all signs of preference to put in first rank the lowest level of nuisance rather than the highest one. Another point is that we did not divide the flows by $(n-1), n$ being the number of items in (2), like in the classical method, in order to point out the maximum number of possible dominances.

We followed this simplified PROMETHEE demarche for each point of view using data from Tables 6 and 9 . The results are exhibited in Table 10. Since there are nine areas, the maximum possible value of a flow is eight for one point of view, which would mean that the corresponding area would dominate all other areas according to all criteria in the family. Let us observe that the maximum observed flow is 7.089 for $\mathrm{z} 8$ in the treatment family. For the global viewpoint, the maximum possible value of flow would be $3 \times 8=24$.

PROMETHEE III also provides a possible ranking of the areas according to each point of view, but it includes some uncertainty about the exact value of each area preference flow. Indeed, Brans et al. (1984) observed that PROMETHEE II provided an unique value of the net flow $\Phi(a)$ at the end of the calculus, although the distribution of flows $\Phi(a, b)$ for all $b \in K$ provided a set of different values of multi-criteria preferences. Then the authors suggested, capturing some uncertainty of preference by building an intervals pre-order of compared items, using these general rules of interval ranking:

$a P b$ if the lowest value of the interval of $a$ is greater than the highest value of the interval of $b$ $a I b$ otherwise, i.e., when there is an overlay of both intervals

The interval calculus for an item $a$, proposed by Brans et al. (1984) consists in computing the mean value $\mathrm{m}$ and the 
Table 10

Nuisance flows of the nine areas in decreasing order according to the three points of view and the global flows balance issued from PROMETHEE II

\begin{tabular}{|c|c|c|c|c|c|c|c|}
\hline \multicolumn{2}{|c|}{ Production of HSW } & \multicolumn{2}{|c|}{ Collection of HSW } & \multicolumn{2}{|c|}{ Treatment of HSW } & \multicolumn{2}{|c|}{ Global } \\
\hline \multicolumn{2}{|c|}{ Clearly worse } & \multicolumn{2}{|c|}{ Clearly worse } & \multicolumn{2}{|c|}{ Clearly worse } & \multicolumn{2}{|c|}{ The worst TOP 3} \\
\hline $\mathrm{z} 2$ & 6.069 & $\mathrm{z} 7$ & 3.852 & z8 & 7.089 & $\mathbf{z 2}$ & 6.000 \\
\hline \multirow[t]{2}{*}{$\mathrm{z} 4$} & 5.394 & $\mathrm{z} 3$ & 3.547 & & & $\mathrm{z} 7$ & 5.169 \\
\hline & & & & z3 & 3.078 & $\mathrm{z} 3$ & 4.882 \\
\hline z1 & 1.609 & z9 & 1.183 & $\mathrm{z} 7$ & 1.489 & & \\
\hline $\mathrm{z} 5$ & -0.083 & z6 & 0.147 & $\mathrm{z} 2$ & 0.811 & $\mathrm{z} 8$ & 0.448 \\
\hline z7 & -0.172 & $\mathrm{z} 5$ & -0.730 & z9 & -0.572 & $\mathrm{z} 4$ & 0.404 \\
\hline z6 & -0.654 & z8 & -0.820 & $\mathrm{z} 5$ & -1.643 & $\mathrm{z} 5$ & -2.456 \\
\hline $\mathrm{z} 3$ & -1.743 & $\mathrm{z} 2$ & -0.880 & $\mathrm{z} 4$ & -1.710 & The & \\
\hline \multicolumn{2}{|c|}{ Clearly better } & \multicolumn{2}{|c|}{ Clearly better } & \multicolumn{2}{|c|}{ Clearly better } & z9 & -3.986 \\
\hline z9 & -4.597 & $\mathrm{z} 1$ & -3.020 & z6 & -3.962 & z6 & -4.469 \\
\hline z8 & -5.821 & $\mathrm{z} 4$ & -3.280 & $\mathrm{zl}$ & -4.579 & $\mathbf{z 1}$ & -5.990 \\
\hline
\end{tabular}

The maximum possible flow is eight for one point of view and 24 for the global viewpoint.

standard deviation $s$ of the distribution of the flows $\Phi(a, b)$. Then, the bounding values of the interval are $m \pm \alpha s$. By changing the values of parameter $\alpha$, they could incorporate more or less uncertainty of ranking. Indeed, a greater value enlarges the intervals, often resulting in chains of indifference. A smaller value of $\alpha$ excludes too much uncertainty. There exists an optimal $\alpha$ value which just avoids any chains of indifferences. In our application, we used two simplifications: first, we computed the full interval with the range: $\operatorname{Max}_{b} \Phi(a, b)-\operatorname{Min}_{b} \Phi(a, b)$ for all $b \in K$, then by breaking visually the observed chains, we could avoid concluding to a chain of indifferences. This visual decision required only that a graph could be exhibited with few items, as was the case in our application. Note that the mean $m$ of each inter$\mathrm{val}$ is the net flow given by PROMETHEE II.

The PROMETHEE III graph is exhibited in Fig. 3. For instance, a chain of indifferences is observed for the areas $\mathrm{z} 2, \mathrm{z} 7, \mathrm{z} 3$ in the TREATMENT and it is visually obvious that z3 is "preferred" to z2 in the sense of higher nuisance. In this graph, the dominant areas in terms of nuisance are on the right of the graph, and the dominated areas are on the left. Thus, these latter dominated areas are better due to their comparatively smaller nuisance.

The next step was the simultaneous consideration of the three rankings points of view by using the judge's tools issued from ARGOS and JUDGES. Fig. 4 is the simple linkage hierarchical clustering of the three rankings given by the three points of view. Fig. 5 is the box-plotting of the distributions of ranks given to each area by the set of three points of view that are the three judges of nuisance. The extreme values of the boxes shown in this graph are, respectively, the third quartile and the first quartile of the distribution of ranks given by the judges. Accordingly, the greater a box, greater the disagreement between the three judges of nuisance on an area. Inside the box is a bold line marking the median rank given by the set of three judges; this is obviously a way of ranking the areas with a global point of view.
Actually, there exist numerous ways to provide a global aggregated ranking of items. Most of them search for a kind of consensus of ranking reached among the different judges; this methodology is included in ARGOS.

In this paper, we have only considered three ways to aggregate the three points of view in order to obtain a final unique ranking of the nine areas.

The first one is very simple, having the advantage of easy calculus and understanding by the reader. It consists of adding the preference flows of each area of the three points of view and of ranking the areas according to the decreasing order of their sums of flows. These sums and the aggregated ranking of areas according to the global view are exhibited on the right-hand side of Table 10. Let us observe, however, that this simple way of aggregating the ranking has the disadvantage of compensating the different rankings of the three basic points of view, and therefore should be interpreted with caution.

The two other ways of aggregating the points of view take more account of the discordance observed in the three basic rankings. This is the reason why their results differ from those of the simple approach. The first way is the ranking by the medians of judges rankings, which lets some ties appear $(\mathrm{z} 2, \mathrm{z} 7)$ and $(\mathrm{z} 6, \mathrm{z} 9)$. The second way is the function of BORDA that provides a global ranking of consensus between the judges for the areas. A single tie $(\mathrm{z} 2, \mathrm{z} 7)$ is observed for the second worst level of nuisance in all the areas, $\mathrm{z} 8$ being the area with the highest level of nuisance. In order to avoid the compensation effect, we will retain this last way of aggregating and ranking the relative levels of nuisance:

The function of BORDA provides a global index of relative nuisance for the areas, starting from the lowest nuisance value of 6 for the area $z 1$ until the highest one of 17 for the area $z 8$. 


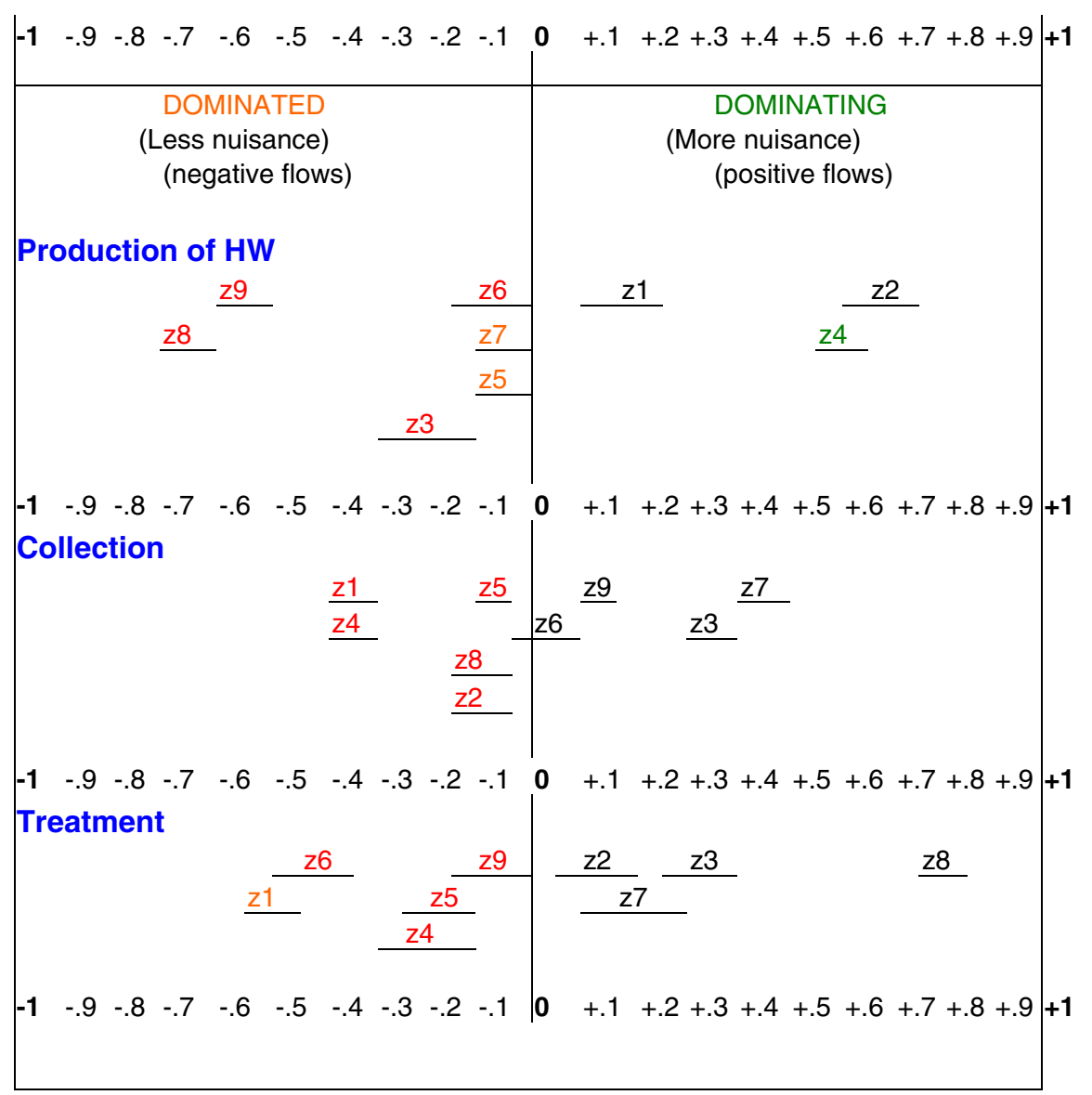

Fig. 3. Graph of the nuisance flows intervals obtained from PROMETHEE III for the three points of view.

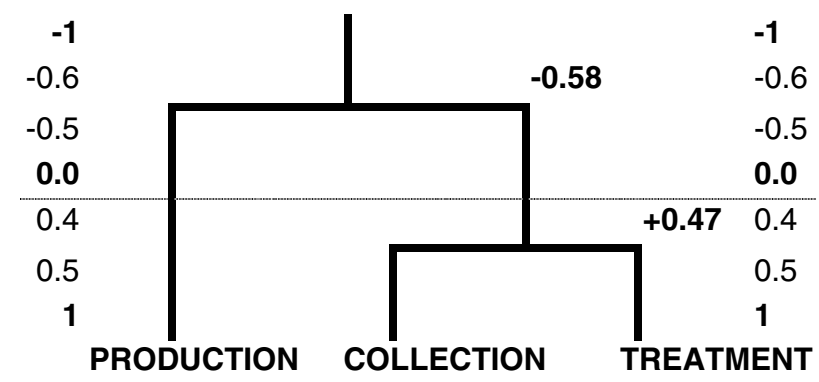

Fig. 4. Extract of the simple linkage hierarchical clustering for the three points of view.

\subsection{Technical results obtained by the software ARGOS (Table 10 and Figs. 3-5)}

The results given by PROMETHEE II and III are summarized in Table 10 and Fig. 3, and they are grouped in clusters of proximate preference net flows, according to each of the three viewpoints. The global point of view may be issued from an addition of results of the points of view and it is shown on the right-hand side of Table 10 , but is better measured by the BORDA index in Fig. 5.
In terms of the $H S W$ production objective, the areas $\mathrm{z} 2$ and $z 4$ are clearly worse in terms of nuisance and $z 8, z 9$ clearly better, while $\mathrm{zl}$ is still dominating the others in terms of relative nuisance. In terms of the $H S W$ collection objective, the areas $\mathrm{z} 7$ and $\mathrm{z} 3$ are clearly worse in terms of nuisance and $\mathrm{z} 1, \mathrm{z} 4$ clearly better, while $\mathrm{z} 9, \mathrm{z} 6$ are still dominating the others. The HSW treatment reveals a clearly worse nuisance in area z8 and clearly better areas z1, z6, while $z 3, z 7$ and $z 2$ have a dominating nuisance. All these results are confirmed by the interval orders given by PROMETHEE III, in Fig. 3.

A simple comparison of the three rankings given by the three points of view reveals a positive correlation $(+0.47)$ of the rankings of areas between the "judges" COLLECTION and TREATMENT, while a minimal negative correlation $(-0.58)$ is observed between the PRODUCTION ranking and any of the two other viewpoints (see Fig. 4). This latter negative correlation is mainly explained by the consideration of the criteria "duration between collections" and "frequency of collection" per week, respectively, in the production and the collection points of view, recalling that the criterion 'duration' is the inverse of 'frequency'.

So, this means that the global point of view is too strongly compensating these opposite results, as shown in 


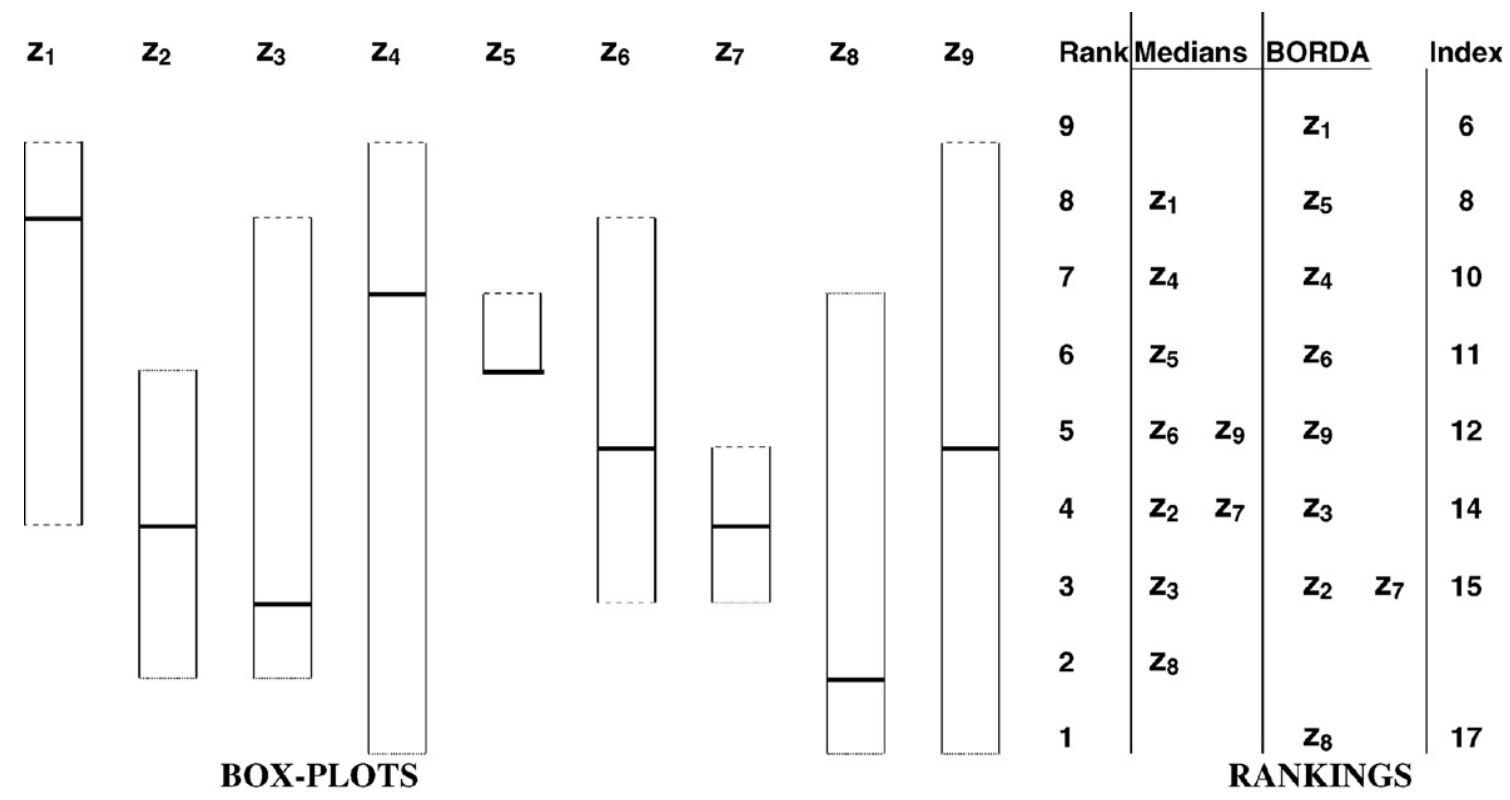

Fig. 5. Box-plotting of the nine areas by the three points of view rankings and their global BORDA ranking of relative nuisance.

Table 10 on the right: $z 2$ seems to be the worst area followed in the worst top 3 by $z 7$ and $z 3$, while the best top 3 are $z 9, z 6$ and $z 1$, this last area being the one with the least relative nuisance from a global point of view.

The box plotting confirms the spread of rankings with their long boxes, demonstrating the difficulty of concluding from a global viewpoint. Therefore, the ranking by the BORDA index of relative nuisance could be preferable, let us recall it:

The best area would be $z 1$ and the worst area would be $z 8$, while $z 2$ and $z 7$ would have equivalent second worst relative nuisance.

\section{Interpretation of the results by using our field knowledge} (Fig. 6)

\subsection{The point of view of $H S W$ production}

According to Table 10 and Fig. 3, the area $z 2$ is the worst one in terms of nuisance level, followed by $\mathrm{z} 4$, while $\mathrm{z} 8$ is the best area. We observed also that the three areas $\mathrm{z} 2$, $\mathrm{z} 4$ and $\mathrm{z} 1$ are dominating the others regarding nuisance. Areas $z 8$ and $z 9$ are strongly the best areas, and in the middle ranking, areas z6, z7, z5 and z3 appear dominated by others with more nuisances, i.e., they are rather good.

Area $\mathrm{z} 2$ presents the highest level of waste production in $\mathrm{kg}$ /households (9.09) and is the most crowded $(36,600$ households). In SA, area $\mathrm{z} 2$ is the first industrialized area that has attracted more people. Area $\mathrm{z} 4$ has nearly the same characteristics but it presents the highest level of collection duration in all areas, and this explains the overlay in Fig. 3 between areas $\mathrm{z} 2$ and $\mathrm{z} 4$. Area $\mathrm{z} 1$ is the most beautiful tourist area of Dakar, where the main official and administrative buildings are located, as well as the richest inhabitants of the city. This explains the lower figures in Table 6 . The best areas $z 8$ and $z 9$ are far away from area $z 1$ and are semirural; they have less population and the frequency of collection is higher. This latter observation is explained by a different behaviour with respect to the HSW: the population evacuates its garbage more quickly, but as seen in the treatment point of view, the cultural means are very bad for area $z 8$. The good ranking of area $\mathrm{z} 3$ must not be considered as a good sign since it is mainly due to few households (8300) but at the same time, these households display rather bad HSW behaviour. Indeed, they produce the second largest amount of waste per household and they use the second worst cultural means of elimination with a high collection frequency, like z8. Note, however, that, in the structured areas area z3 is the most resistant to paying taxes for garbage collection and treatment (29.4), probably due to the fact that the residents suffer from the highest level of tax charges linked to their number of houses.

As shown on the map (Fig. 6), the landfill is located close to the sea, inside areas z5 and z6. Area z6 has the largest number of households $(38,000)$ and has the sad privilege of having the highest rate of morbidity $(61.9 \%)$, while the mean rate for Dakar is $30.4 \%$. The presence of the landfill might explain the lowest level of $\mathrm{kg} /$ household (2.7). Area z6 is a semi-rural area, whereas z5 is more urban. We finally observe that the areas $\mathrm{z} 5$ and $\mathrm{z} 7$ are very similar according to the three criteria in the production point of view and this is not a surprise considering their location on the map.

\subsection{The point of view of HSW collection}

Area $\mathrm{z} 7$ is the worst area according to this point of view. Indeed, it is the second worst area in the resistance to pay taxes (50), after z9 (100), and it has the third worst ranking 


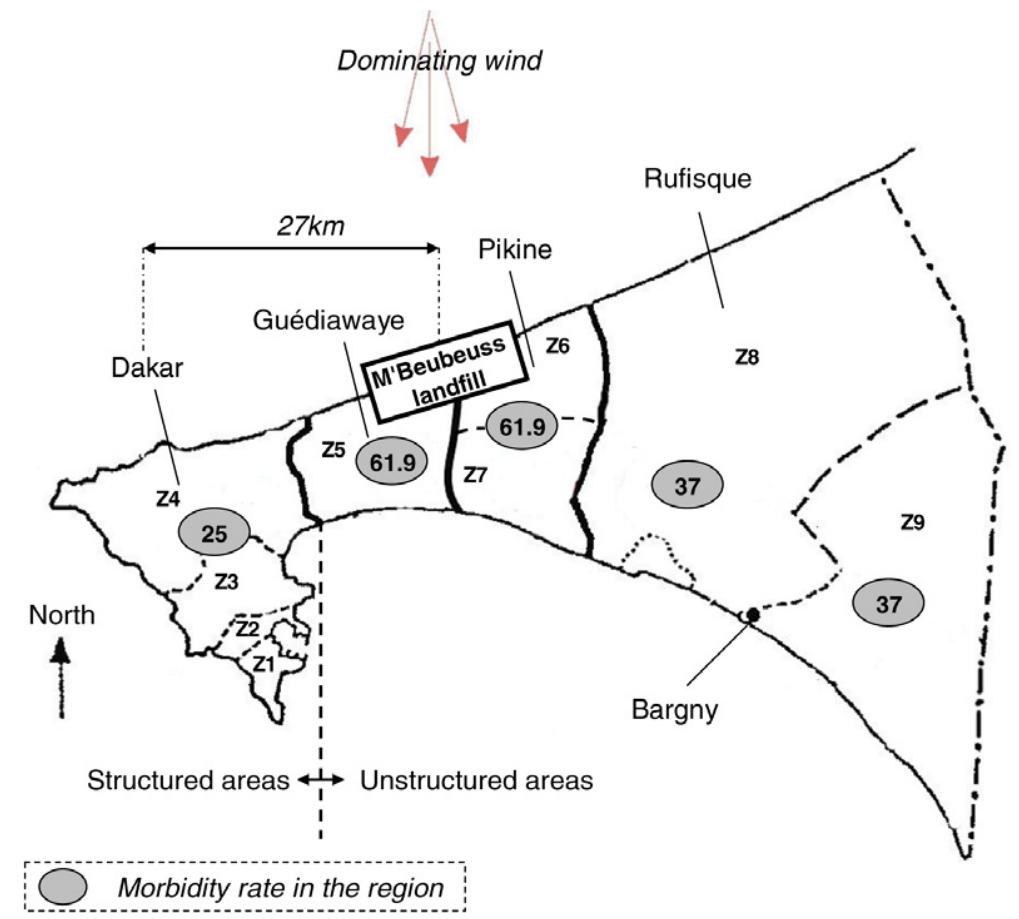

Fig. 6. Map of the Urban Community of Dakar and its nine areas.

in using collection means (0.62). A possible reason is that some rich people have built houses in this area and can dispose of their garbage by compactor truck collection; this rich segment of the population constitutes a niche, which biased the mean of the sector. Area $\mathrm{z} 3$ is remarkable in having the worst use of collection means $(0.71)$ and a low frequency of collections (6th, 5.14). Area z9 presents an exceptional resistance to pay taxes, since this population is poorer. The structured areas $\mathrm{z} 1$ and $\mathrm{z} 4$ are very similar according to the three criteria. In summary, we have shown a strong negative correlation between the two first points of view: production and collection.

\subsection{The point of view of HSW treatment}

Area $\mathrm{z} 8$ is clearly the worst area with its first rank reached in all criteria of this family: respectively, $132 \mathrm{~m}$ in walking distance to the collector, 4.9 in cultural means and one for the perceived nuisance by the rural population. In this area, compactor trucks do not come and the population does not care much for their method of eliminating garbage. Area z3 is an industrial area where the collection points are more widely spaced $(110 \mathrm{~m})$ and accordingly, the HSW behaviour of people is poor like in area $\mathrm{z} 8$ (4.71); the perceived nuisance is high. Areas z2 and z7 have similar results, except for the shorter walking distance of area $\mathrm{z} 2$ $(79 \mathrm{~m})$. The cluster of areas $(z 9, z 5, \mathrm{z} 4)$ do not have the same perception of nuisance. While $\mathrm{z} 9$ has a full perception (1), z4 has a high perception (0.83) but z5 has the lowest one despite some of its population being close to the dumpsite. The other area $\mathrm{z} 6$ has some population very close to the dumpsite and it benefits from the shortest walking dis- tance to dispose of its HSW $(9.5 \mathrm{~m})$. The residential area $\mathrm{z} 1$ is characterized by the best performance in terms of cultural means of HSW elimination (3.27). It also has a short walking distance but a very high perception of nuisance.

More generally, we observe a significant positive correlation between the distance and the cultural means of HSW elimination $(r=+0.792)$. We can interpret this as follows: a short walking distance to a collection point has a positive influence on the behaviour of the concerned population. Surprisingly, the distance does not influence the perception of nuisance $(r=+0.12)$ and the choice of elimination means is not a function of this perception $(r=-0.14)$. These issues of the sample, if confirmed in the population, could be usefully employed in the remediation of HSWM problems.

\section{Some suggestions for the remediation of sanitary, economic, aesthetic and environmental HSW problems in the urban community of Dakar}

As already mentioned in the introduction, we justify the proposed following general remedies mainly by recent field observations conducted during our visits in Dakar, confirming that there have been few changes if any in the behaviours already observed and issued from the available research in 1998. Therefore, we are also confident in the relative stability of the ranking of the nine areas of the Urban Community of Dakar and in the specific remedies that we proposed hereafter. Obviously, however, any dramatic change in the HSWM context in Dakar should require an adjustment of our conclusions. It is still the case that the 
multiple criteria methodology would remain useful in another context of analysis and decision aid.

\subsection{The situation of HSWM in the urban community of Dakar}

The Dakar region has an area of $550 \mathrm{~km}^{2}$, with a population of more than 2 million inhabitants (in 1998) with an increase of 100,000 inhabitants per year, mainly due to persons migrating from rural regions of Senegal, often pushed by the desertification. Inside this region, the Urban Community of Dakar (UCD) covers $217 \mathrm{~km}^{2}$ with an area located on a Peninsula and it includes the municipalities of Dakar, Pikine, Guédiawaye, Rufisque and Bargny (see map in Fig. 6). The climate is tropical semi-arid, with a micro-climate that is fresh and humid on the Peninsula.

The rate of birth is $40 \%$, the rate of mortality attains $20 \%$ and the expected life is only 48 years. The UCD mean rate of morbidity is $30.4 \%$, but it strongly varies among the subdivisions of UCD: from $25 \%$ in Dakar city to $61.9 \%$ in Pikine and Guédiawaye, close to the only official landfill, called M'Beubeuss, and 37\% in Rufisque and Bargny. It is highly likely that the highest morbidity rate of $61.9 \%$ is due to the proximity of $\mathrm{M}^{\prime}$ Beubeuss that covers 600 ha and receives more than 395,000 tons per year of household solid wastes. This amount represents $86.43 \%$ of the 457,000 tons per year put in this landfill, $13.57 \%$ being industrial and hospital wastes. Of course, a significant part of the HSW produced by the UCD does not reach the landfill, ${ }^{4}$ either due to recovery during collection or mainly due to the use of numerous small, illegal dumpsites.

For the UCD, a consortium (Senegal-Canadian) is in charge of HSW collection and of its transportation to the official landfill, located $27 \mathrm{~km}$ from the heart of Dakar. ${ }^{5}$ The consortium has 23 compactor trucks and 142 open trucks, used in the structured areas and in the parts of unstructured areas where access allows collection of HSW door-to-door. Elsewhere, they have situated intermediary containers where the population can bring and discharge their garbage. Obviously, an irregular picking of containers by the firm provokes rapid wild dumps close to them. We must observe that the financing of collection and transportation of HSW is partly covered (only 30\%) by municipal taxes (TOM $=$ Taxe pour Ordures Ménagères) based on the ownership of land and buildings. The TOM does not apply to many waste generators (plants, cults, some individuals) and to new areas of urbanization in the unstructured areas.

The mean composition of wastes is known for each of the nine areas. In areas z1, z2, z3 and z5, more than $60 \%$ of HSW is kitchen residues and vegetable plants that are biodegradable. The percentage of biodegradable material

\footnotetext{
${ }^{4}$ (18-41\%, see p. 113, Table II.12, SEDEP in Kapepula).

5 Initially, this landfill was outside the city, but the progressive urbanization has surrounded it, so that the closest neighbours are already less than $100 \mathrm{~m}$ away from it, which is prohibited.
}

reaches $50 \%$ in the semi-rural areas $\mathrm{z} 7-\mathrm{z} 9$. Those percentages in the more industrial areas $\mathrm{z} 4$ and $\mathrm{z} 6$ are $30 \%$ and $40 \%$, while their portion of papers and cardboard reaches one-third of HSW.

\subsection{General remedies to HSW problems for the whole urban community of Dakar}

According to our field knowledge of the actual situation, we will list the main possibilities of general remediation for better HSWM in the Urban Community of Dakar. First of all, we are convinced of the necessity of reducing the solid waste production and the collection at the source, i.e., in each household but also in each institution (schools, administration, etc.) and in hospitals. ${ }^{6}$ Special collection could be organized to pick up recoverable components, sorted from within the solid waste produced by both households and institutions, avoiding the wasting of recyclable components. This organization would drastically reduce the volume of solid waste conveyed to the landfill, while diminishing the feeling of nuisance associated with solid waste. Table 11 shows the main possibilities of HSW recovery. As shown in the table, metal, textile, rubber and glass are the materials most recovered by households and also during the travel from door to landfill.

More generally, let us quote Rotich et al. (2006) who said: "The problems facing developing countries in handling of municipal solid and liquid wastes... need concerted effort from all sectors of society. An all inclusive approach should be adopted on order to achieve any meaningful and lasting solution". These authors propose the adoption of the three following general remedies:

1. Source reduction and reuse: this reduction "involves a minimization of waste reaching the drop off points". In Kenya, for example for reusing packaging, "local artisan groups are involved in producing inexpensive farm tools such as sprays and watering cans". These low-cost products have a big market among the lowincome population.

2. Recycling of municipal solid wastes: this provides a cheaper source of raw materials for manufacturing industries.

3. Privatization and community involvement: "with privatisation of MSW services in the upper and middle income areas, local authorities can... divert some of the services to poor suburban areas communities where private services may not be affordable".

Let us consider eight other possible general remedies for the HSW problems resulting from our field observations during our visits. Some of the remedies are also proposed in the literature.

\footnotetext{
${ }^{6}$ This problem of collection and treatment of general and hospital wastes was already successfully addressed in a Belgian study done by Kapepula in the 90s. This study allowed the Liege University Hospital to reduce its hospital wastes invoice by $225,000 €$.
} 
Table 11

Potential waste recovery options in the Urban Community of Dakar

\begin{tabular}{|c|c|c|c|c|}
\hline & Type of recovery & $\%$ & Components & $\%$ \\
\hline \multirow[t]{7}{*}{ Recyclable } & Biodegradable & 66.68 & Kitchen and vegetables residues & 56.34 \\
\hline & & & Wood and leather & 0.82 \\
\hline & & & Paper and cardboard & 9.52 \\
\hline & Non-biodegradable & 12.66 & Plastics & 6.23 \\
\hline & & & Textiles & 2.87 \\
\hline & & & Metal parts & 1.87 \\
\hline & & & Rubber and glass & 1.69 \\
\hline \multirow[t]{3}{*}{ Non-recyclable } & Special wastes & 2.15 & Batteries and drugs & 2.15 \\
\hline & Various & 18.51 & Thin matters & 14.15 \\
\hline & & & Others & 4.36 \\
\hline Total & (In tons: 395,075 ) & 100.00 & & 100.00 \\
\hline
\end{tabular}

Source: Kapepula, thesis, 2006, p. 142.

4. HSW sorting at home: all of the members of a household can take part in the sorting of waste. With this intention, it is possible to benefit from the motivation of women who often fear the insalubrious environment, the danger of bad sanitary conditions and the risk of injury and health problems, especially for their children who habitually convey garbage to intermediary containers. The women's motivation could be increased by their awareness of the recyclable and recoverable values of HSW.

5. Giving special receptacles for facilitating separation of different types of $H S W$ with the view of material recycling: giving special receptacles is a source of motivation to sort HSW by type. For instance, the removal of organic wastes from the general waste collection would reduce significantly the volume of collection $(>50 \%)$. This removal could increase the justification of using packer bodies (compactor trucks) in a developing country like Senegal. Indeed, compactor trucks are generally misused in such countries, where the garbage is wetter and denser than in industrialized countries due to its high percentage of organic matter. The sorting of recyclable materials from HSW and selling the materials to itinerant merchants would be facilitated by these special receptacles with three or four compartments. Savings in transport costs might contribute to financing this remedy if the following remedy is undertaken.

6. Providing tricycle-vans and pushcarts to scavengers or itinerant merchants, andlor to associations:

Similar to other comparable cities, the informal economy of scavengers is very active in the city of Dakar. In developing countries, scavengers are often exploited by middlemen who sometimes take a monopolistic position, leveraging their profit by buying materials from scavengers at a very low price, and then selling the materials to industry at a high price. Since scavengers are very poor, they have adopted this business as a struggle for life. Some of them are more competitive, being close to the landfill or even being waste pickers in the landfill itself. Providing tricycle-vans or pushcarts to the other (less competitive) scavengers will increase their ability to compete. Since there is so much work available in the collection of HSW by such means, it would remain a context for organizing associations of people taking on a part of this job on a voluntary or remunerated basis.

7. Financing equipment for sorting and collection by micro-credit:

The year 2005 was declared the micro-credit year in the world. Let us recall that micro-credit has been invented by Prof. Muhammad Yunus in Bangladesh since he observed that:

(a) Some very poor people have innovative ideas of creating simple jobs or micro-enterprises and they want to do it.

(b) They just lack some money to start their job and, eventually, to buy some basic equipment.

(c) Since these people were previously applying for very small amount of credit without any warranty, the banking system was unable to give a positive answer. This is no longer the case with the recent development of financial micro-credit channels and institutions and the NGO involvement.

(d) It has been proven that poor people pay back loans better than rich people if they are not over-indebted.

(e) Several experiences with women and men in developing countries have proven that the success of micro-enterprises is far higher with women, since they are more concerned about the micro-enterprise they can create, and more keen in money management and in paying back the money borrowed. Furthermore, women are dignified by the responsibilities they undertake, and this is a further motivation of success.

(f) A frequent condition of the micro-credit success is reached when women are organized in small associations of borrowers that can support their con- 
fidence in entrepreneurship and their willingness to repay the money they have borrowed. Often, such an association becomes the kernel of other associations with the purpose of improving the household living conditions. ${ }^{7}$

So, our priority recommendation is to finance small local associations of women by micro-credit in order to buy basic equipment for sorting and collecting some of the HSW. Let us observe that some women's associations exist already in Dakar, so that the creation of micro-credit based associations may be facilitated. More generally, associations of scavengers, males or females, could benefit from such a financing device.

8. Government support for cooperatives of scavengers (or itinerant merchants): it has been observed that creating cooperatives of scavengers is a powerful way for

\footnotetext{
${ }^{7}$ Since the micro-credit concept by Yunus, this device oriented to the improvement of the situation of lower-income people has been largely exploited for the poorest communities in the world with a focus on the formation of women's group. Discussions and debates in social forums and in the literature have questioned, in various dimensions, the real positive or even negative impacts of micro-credit and, more generally, of micro-finance. The debates question the poverty reduction by low-income leveraging, the social, medical and environmental impacts, while the assumed high rate of reimbursement and micro-enterprises successes becomes a study of research in the financial community. Also, two main principal techniques of micro-credit are discussed: for example, Denotes and Kritikos (2004) ask: "is the individual micro-lending contract a better design than joint-liability?". These authors say that very high repayment rates, up to $100 \%$, can be similar if different incentives are used in both cases. For the debate on successful small enterprises in Africa, see Rogerson (2001). Thorp et al. (2005) observe that group-formation, often recommended in micro-credit, can improve the situation of the better-off poor people at the expense of the poorer: "successful groups formed among the poor often exclude the even poorer" (p. 907). About the frequent microcredit support by NGOs, Premchander (2003) underlines that the interests of people and those of micro-financing institutions (MFIs) sometimes compete and conflict: "When funding support underlines financial viability, the MFIs have to be competitive; poverty reduction and empowerment will suffer unless the institutions are also owned and managed by the poor (an idea of Yunus) ... NGOs can provide leadership for greater structural reforms and do what they are best at: be facilitators, and create people institutions for micro-finance" (p. 361). Anderson et al. (2002), investigating the impact on small loans to poor borrowers on common pool resources, said: "Enhanced human and social capital can improve (in turn) environmental outcomes. A non-random survey of micro-finance organizations suggests increased environmental awareness and potential common pool stewardship through micro-credit..." (p. 95). Finally, but not the least point for our study, the evidence of positive medical impact of a womenfocused development programme on child survival in Bangladesh is presented by Bhuiya and Chowdbury (2002). They stated that, in a medical survey about 13,549 children born alive during 1988-1997, there was a substantial reduction in infant mortality observed for the group of women participating to the program with micro-credit relative to the group of non participating women. Syed and Chowdbury (2001) also studied mental stress of poor rural women implied in such programs in Bangladesh without the evidence of a significant difference between participants and non-participants at a micro-credit programme. However, some violence against participating women, perpetuated by their husbands, have been sometimes signalled. The reasons were that participating to these activities necessitated a transgression by women of social and religious norms.
}

scavengers to improve their income and living conditions. It is important that they are acknowledged by the government; this is another way of creating a private/public partnership. There may be some resistance from the middlemen, who are also in the informal sector. The government that can negotiate with these often-required intermediaries should regulate this. Also, a possible obstacle to this cooperation policy is some resistance coming from scavengers and itinerant merchants to be acknowledged by the government, for obvious fiscal reasons or threats of regulation.

9. Creating "controlled containers parks", or how to move from a situation of uncontrolled landfill to the use of containers parks: the huge landfill of M'Beubeuss was under control at the beginning of the 1960s, when it was devoted to the residues coming from a composting industry. Since this industry was not successful, the landfill was progressively open to accept various kinds of wastes, and with the growth of urbanization around it, the control of wastes was abandoned. The proposal is to close M'Beubeuss and to create a smaller controlled disposal site where only non-recyclable residuals may enter. Several small, controlled container parks would receive the sorted wastes. Middlemen and recyclable material buyers could enter these parks with an identity card and a pass for purchasing the sorted materials that would be inventoried on a computer in order to have a better knowledge of the HSWM system. They could buy a pass card at a governmental agency. Without the pass and identity card, no access to the park would be allowed.

10. Using the M'Beubeuss landfill to produce biogas and energy?: in Tanzania, a big project has been launched to provide electric energy based on the use of biogas extracted from a large landfill (Mbuligwe and Kassenga, 2004). A study on the possibility of extracting biogas from the M'Beubeuss landfill was conducted with the participation of Kapepula and the expertise of Philippe Thonart. A sufficient humidity in organic wastes is necessary to produce biogas. Now, wastes in M'Beubeuss are rapidly very dry and the humidity gained from rain (34 full days each year in Senegal) would be only sufficient over a short period (less than 1 month) so that a biogas production by M'Beubeuss is probably technically and economically unfeasible. The alternative would be to close the landfill and to develop a smaller one, that would strictly serve as a simple disposal site for final residuals, after a thorough recovery process for recyclable materials all through the supply chain of waste management, beginning at home and in the streets, then at the small container parks to be created.

11. Economic, safety and environmental awareness and education of the population: obviously, most of the previous remedies cannot be successful if sufficient information and economic, safety and environmental 
sensitivity is not diffused to the solid waste stakeholders and to the whole population. See, for example, the recommendations by Ojeda-Benitez et al. (2003) for the city of Mexico:

"It is important to create specific work programs ... to promote in community residents pro-environmental behaviour such as reduction in consumption ${ }^{8}$ and the practice of re-utilization and recycling. However, these programs require to be accompanied by municipal campaigns for the collection and sales of recyclable wastes ... (Also) programs of environmental education must be created, so that the activities of separation, re-utilization and recycling may acquire a deeper meaning for the individual, rather than being taken as tasks imposed for bureaucratic reasons."

Let us also quote an original promotion and encouragement of a community-based solid waste management initiative in the paper by Mongkolnchaiarunya (2005). The author states that, in the Yala municipality in Thailand: "Residents were encouraged to bring recyclable material to exchange for eggs, at monthly exchanges in local communities, with emphasis on poorer communities. The project aimed not only at garbage reduction, but also at community empowerment through self-reliance, establishing new relationships of more equality and less dependence, between poor communities and the municipal administration ... Following the principle of changing "trash to treasure", the egg is used as an exceptional means for mobilizing public participation in waste separation and recycling." Of course, such an original initiative must be adapted to the local culture.

Rotich et al. (2006) state in their conclusion: "Regular activities such as clean up of the neighbourhoods, schools, parks and roadsides can be effective in changing the "NIMBY" attitudes even among the poor communities... These attitudes may be influenced by awareness-building campaigns and educational measures".

Whatever the adopted system and programs of motivation, small attempts with some of the remedies should serve as pilot experiments for gaining experience and mostly to create dynamic "word of mouth messages" of successful efforts. The agenda of change is by no means negligible.

\subsection{Specific remediation for different areas}

The structured areas $z 1-z 4$ are generally richer than unstructured areas $\mathrm{z} 5-\mathrm{z} 9$; the roads are better, the doorto-door collection is easier and the packer bodies could continue collection there. Also, the specific administrative and tourist area $\mathrm{z} 1$ may consider as a question of prestige to con-

\footnotetext{
${ }^{8}$ In poor communities, the reduction effort is not to be brought on consumption food that is often insufficient. Also, let us recall that the customs of alimentation by the African consumers are different, since they eat more fresh vegetables, fruits and fishes, due to their low income. Accordingly, the organic wastes are composed of such highly recyclable residues in abundance.
}

tinue this modern and clean way of HSW collection. Inside SA areas, z2 has the highest volume of waste production, also when it is reported by each household. This area $z 2$ is heterogeneous in terms of income per house and rather crowded $(364,000)$, so there is a possibility of mixing modern collection vehicles (like compactors trucks) and some general remedies quoted in the previous subsection. Indeed it is necessary in $\mathrm{z} 2$ to diminish the too great waste production, especially by separating at home organic materials from others and by organizing their special collection. Although the $\mathrm{z} 4$ area also has many inhabitants and, consequently, a rather large amount of waste produced, the situation is better so that there is no specific recommendation. For the area $z 3$, which is more industrial, the recovery of $30 \%$ of paper and cardboard in its HSW could be a good valorisation, obtained by a special collection.

The unstructured areas present different problems: more containers and fewer compactor trucks, the presence of the landfill inside $\mathrm{z} 5$ and $\mathrm{z} 6$ and more rural habits in $\mathrm{z} 8$ and $\mathrm{z} 9$. Furthermore, the illegal extension of habitat in these areas creates a mixture of rich and poor people and a great variety of behaviours. Consequently, it would be necessary to make further detailed studies in order to design special policies that are adequate. The better control of the open landfill would improve the sanitary situation of its neighbours z5 and z6. Obviously the weak volume of waste per household in the area $z 6$ is probably due to a greater number of wild dumpsites. Scavengers' cooperatives could be first launched in this area, with z6 becoming a pilot zone for testing the proposal. The area $\mathrm{z} 7$ has the lowest mean income and should be considered as a priority in implementing HSWM, with an income-leveraging objective. In z7 and z8, the walking distance to collectors is too high; thus it implies more need for pushcarts and micro-credit for women and scavengers' cooperatives. The semi-rural area $\mathrm{z} 9$ has the poorest population, but this population is more accustomed to deal with their HSW by themselves: this could be encouraged while information and training to valorise some of the HSW could be advantageous.

\section{Conclusion}

In this paper, we have proposed a first study using a multiple criteria and multiple viewpoints analysis of the household solid waste management (HSWM) for the Urban Community of Dakar. This analysis has mainly produced three rankings in terms of relative nuisance of nine areas of this community, according to the three general objectives: the production, the collection and the treatment of HSWM. These rankings had the purpose of discovering the worst and best areas in terms of nuisance, in order to find specific and general remedies to the problematic situation of HSWM in this city of a developing country. Also, a general ranking and an index of nuisance using the function of BORDA have been proposed and discussed. This general ranking can be questioned because of the difficulty of finding sufficient, reliable, and relevant and updated 
data for building proxy-measures of nuisance. Further studies could produce more refined and more recent indicators for this measure of nuisance. Nevertheless, the chosen set of criteria is a first attempt to build a cartography of HSW nuisance and, accordingly, to suggest some measures of improvement that are specific for each area. By an exploration of the literature and mostly by several field observations, we proposed a set of general remedies for the whole Urban Community of Dakar. None of these remedies can be considered as a panacea and their application should be considered with all of the required prudence. We must also consider that micro-credit is an instrument useful for improving the HSW sorting that is basic for providing a good return in the recycling sector and let us recall that the development of small enterprises is very important in Africa. Pilot experiments probably should be tried before a more general application and their hopefully successful results could encourage further improvements. Here the methodology of this cartography of nuisances may be useful to design pilot experiments. The remedies can be undertaken alternatively or as subsets of improvement measures. Indeed, the general remedies, discussed in the previous section for improving HSWM, also constitute a chain of improvement since they can be implemented together, benefiting from their mutual reinforcement. Since some of them, at least, might improve the whole system of HSWM, their impacts in the socio-economics, sanitary and ecological conditions of the Dakar's population - especially and hopefully of the poorest people - would induce virtuous circles in place of the actual vicious ones. This is our hope.

\section{Acknowledgements}

The authors are grateful to Mapapa Mbangala and Caroline Lecomte and to anonymous referees for their useful comments.

\section{References}

Anderson, C.L., Locker, L., Nugent, R., 2002. Micro-credit, social capital and common pool resources. World Development 30 (1), 95-105.

Bhuiya, A., Chowdbury, M., 2002. Beneficial effects of a women-focused development programme on child survival: evidence from rural Bangladesh. Social Science and Medicine 55 (9), 1553-1560.

Brans, J.P., Vincke, Ph., Mareschal, B., 1984. PROMETHEE: a new family of outranking methods in multi-criteria analysis. In: Brans, J.P. (Ed.), Operational Research, vol. 84. North Holland, New York, pp. 477-490.

Brans, J.P., Vincke, Ph., Mareschal, B., 1986. How to select and to rank projects: the PROMETHEE method. European Journal of Operational Research 24 (2), 228-238.
Colson, G., 2000. The OR's prize winner and the software ARGOS: how a multi-judge and a multi-criteria ranking GDSS helps a jury to attribute a scientific award. Computers and Operations Research 27, 741-755.

Colson, G., Mareschal, B., 1994. JUDGES: a descriptive group decision support system for the ranking of items. Decision Support Systems 12, 391-404.

Colson, G., De Bruyn, Chr. (Eds.), 1989. Models and Methods in Multiple Criteria Decision Making. Pergamon Press, New York.

Colson, G., Mbangala, M., 1998. Evaluation multicritère d'entreprises publiques du rail. Fineco 8 (1), 45-71.

Denotes, V., Kritikos, A.S., 2004. The individual micro-lending contract: is it better design than joint-liability? Evidence from Georgia. Economic Systems 28 (2), 155-176.

Ericson, O., Carlsson Reich, M., Frostell, B., Bjorklund, A., Assefa, G., Sundqvist, J.O., Granath, J., Baky, A., Thyselius, L., 2005. Municipal solid waste management from a system perspective. Journal of Cleaner Production 13, 241-252.

Kapepula, K.M., 2006. Contribution à l'amélioration de la gestion de déchets ménagers solides dans les villes des pays en développement. Le cas de Dakar au Sénégal. Thèse de doctorat, Université de Liège, Belgique.

Kum, V., Sharp, A., Harnporchai, N., 2005. Improving the solid waste management in Phnom Penh City: a strategic approach. Waste Management 25, 101-109.

McBean, E.A., del Rosso, E., Rovers, F.A., 2005. Improvements in financing for sustainability in solid waste management. Resources, Conservation and Recycling 43, 391-701.

Mbuligwe, S., Kassenga, G.R., 2004. Feasibility and strategies for anaerobic digestion of solid waste for energy production in Dar es Salaam city, Tanzania. Resources, Conservation and Recycling 42, 183-203.

Medina, M., 2000. Scavenger cooperatives in Asia and Latin America. Resources, Conservation and Recycling 31, 51-69.

Mongkolnchaiarunya, J., 2005. Promoting a community-based solids waste management initiative in local government: Yala municipality, Thailand. Habitat International 29, 27-40.

Ojeda-Benitez, S., Armijo de Vega, C., Ramirez-Barreto, M.E., 2003. Characterization and quantification of household solid wastes in a Mexican city. Resources, Conservation and Recycling 39, 211-222.

Premchander, S., 2003. NGOs and local MFIs - how to increase poverty reduction through women's small and micro-enterprise. Futures 35 (4), 361-378.

Rogerson, C.M., 2001. In search of the African miracle: debates on successful small enterprise development in Africa. Habitat International 25 (1), 115-142.

Rotich, Henry K., Zhao, Yongsheng, Dong, Jun, 2006. Municipal solid waste management challenges in developing countries - Kenyan case study. Waste Management 26, 92-100.

Roy, B., 1996. Multi-criteria methodology for decision aiding. Kluwer Academic Publ., Norwell.

Shafiul, A.A., Mansoor, A., 2004. Partnerships for solid waste management in developing countries: linking theories to practices. Habitat International 28, 467-479.

Syed, M.A., Chowdbury, M., 2001. Micro-credit and emotional wellbeing: experience of poor rural women from Matlab, Bangladesh. World Development 29 (11), 1957-1966.

Thorp, R., Stewart, F., Heyer, A., 2005. When and how far is group formation a route out of chronic poverty? World Development, 907920.

Vincke, Ph., 1992. Multi-criteria Decision Aid. Wiley, Chichester. 